\title{
Characterization of Dissolved Organic Matter at Different Stages of a Tropical Surface Water Treatment Using Fluorescence Spectroscopy (Agboville, Côte d'Ivoire)
}

\author{
Droh Lanciné GONE*, Bamory KAMAGATE*, Raymond LIGBAN*, Issiaka SAVANE*, \\ Jean BIEMI** \\ * Laboratoire Géosciences et Environnement, Université d'Abobo-Adjamé, 02 BP 801 Abidjan \\ 02 - Côte d'Ivoire. \\ ** Centre Universitaire de Recherche et d'Application en Télédétection (CURAT), Université de \\ Cocody, 22 BP 801 Abidjan 22 - Côte d'Ivoire.
}

\begin{abstract}
The quantitative and qualitative evolution of dissolved organic matter was followed at different stages of water treatment and in tap water to assess dissolved organic carbon (DOC) removal. Both DOC and 3- dimensional excitation emission matrix (EEM) fluorescence spectroscopy were used to evaluate the efficiency of the process. On the average, $53 \%$ of DOC was removed during the treatment process at the treatment plant. After water released in the distribution system, an increase of $27 \%$ DOC was observed in tap water, suggesting a production of organic carbon within the network. The EEM permitted to distinguish three main fluorophores, tryptophan-like (T) and humic-like (A and $\mathrm{C}$ ) in raw water as well as in treated water. In tap water, an increase of fluorescence intensity (FI) was also observed, 31\%, 34\% and 59\% on the average for fluorophores $\mathrm{A}, \mathrm{C}$ and $\mathrm{T}$, respectively. The tryptophan-like fluorophore is related to microbial activities and suggests an important development of microbial community within the distribution system due to the inefficiency of organic matter removal during the water treatment process.
\end{abstract}

Keywords: water treatment, DOC removal, EEM fluorescence, tap water, microbial activity

\section{INTRODUCTION}

The demand on water supply has increased over the last decades due to population growth and increase water use. People expect a secure, high quality, water supply and the water supply industry is governed by increasingly stringent water quality guidelines and legislation, ensuring that customers receive the highest quality drinking water at all times (Hurst et al., 2004).

Among the undesirable water quality parameters, dissolved organic matter (DOM) defined as the complex matrix of organic material present in natural waters, significantly affects many aspects of water treatment, including the performance of unit processes (i.e oxidation, coagulation, and adsorption), application of disinfectants, and biological stability (Rizzo et al., 2005). DOM has become increasingly important with regards to water supplies, because it reacts with chlorine during the disinfection process in drinking water treatment and produces disinfection by-products (DBPs) such as trihalomethanes (THMs) (Lee et al., 2006; Sharp et al., 2006). The formation of THMs is a huge concern because of their carcinogenic effects on humans (Tardiff, 1977, Krasner et al., 1994). Aquatic humic substances, comprising fulvic and humic acids are the most common precursors of THMs. Organic matter in natural water can also cause 
bad odour, taste, colour, and bacterial regrowth problems (Yan et al., 2006) within water distribution systems.

Of these DOMs, coloured humic substances (mainly humic and fulvic acids) generally predominate, and a large proportion of these substances are soluble. Coagulation is one of the most commonly used methods for the removal of DOM. Traditionally, the primary purpose of coagulation is to remove turbidity from water (Ye et al., 2007). With the recognition of disinfection by-products, dissolved organic matter removal through enhanced coagulation is being widely adopted in the world. To evaluate the efficiency of DOM removal, dissolved organic carbon (DOC) is the principal parameter analyzed in water treatment plants. However, the determination of DOC does not give enough information about the nature of DOM because; DOM is a mixture of compounds with variable reactivity during water chlorination. DBPs are produced by natural organic matter (NOM), consisting mainly of humic substances, whereas DOC comprise NOM and also industrial and domestic wastewaters organic matters input.

Fluorescence spectroscopy has been widely used to investigate the chemical property and source of DOM in natural waters. In particular, 3-dimensional excitation emission matrix (EEM) fluorescence spectroscopy has been successfully used to probe the chemical structure of DOM because it can distinguish among different classes of DOM of different origins (Coble et al., 1990; Wu et al., 2003; Baker and Spencer, 2004). EEM spectra are acquired by sequential fluorescence emission scans at successively increasing excitation wavelengths, and consist of three-dimensional spectra showing excitation and emission wavelengths and fluorescence intensity. They are presented as contour maps of the fluorescence landscape with iso-intensity levels delineating various peaks. An EEM typically covers a range of excitation and emission wavelengths from $200 \mathrm{~nm}$ (short wavelength UV) through to $500 \mathrm{~nm}$ (visible blue-green light), and may contain fluorescence centres that are attributable to both natural DOM groups such as humic and fulvic-like material, as well as fluorescent protein-like material (Coble, 1996; Baker, 2001). Coble (1996) named the humic-like (mainly humic and fulvic acids) material fluorescence centres as fluorophores $\mathrm{A}$ and $\mathrm{C}$, and protein-like material fluorescence centres as fluorophores $\mathrm{T}$ and $\mathrm{B}$.

The objective of this study is to use both DOC and EEM to evaluate DOM removal and characterize DOM at different stages of water treatment.

\section{MATERIALS AND METHODS \\ Water source and treatment}

The raw water comes from the Agbo water reservoir, located in Agboville (Côte d'Ivoire) under tropical climate. This reservoir results from the construction of a dam on the Agneby river body in order to supply water to Agboville. The reservoir is colonized by aquatic plants and affected by municipal wastewaters. The raw water treatment process is shown in Figure 1. Owing to its low cost, chlorine is the chemical oxidant used at the treatment plant for pre-treatment (pre-chlorination) and for post-treatment (disinfection) to maintain a disinfectant residual in the system. After coagulation-flocculation using aluminium sulphate, sedimentation, in the filtration stage, homogeneous sand bed is used. At the end of the treatment process, before the release of 
water to the distribution system, the $\mathrm{pH}$ is adjusted with lime to limit the corrosion of the distribution material.

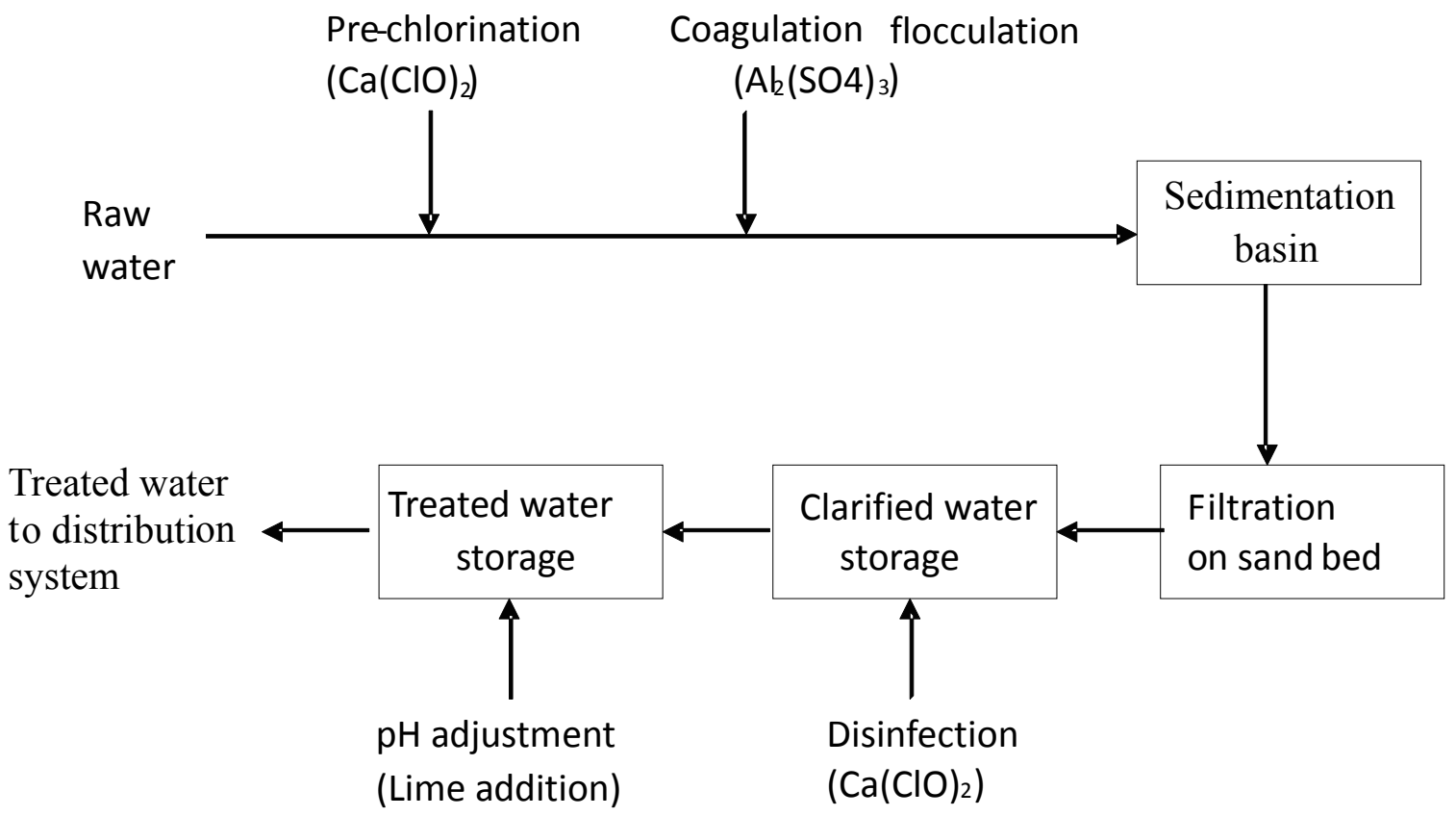

Fig.1 - Stages of water treatment process in Agboville

\section{Sampling}

Raw, clarified, and treated water from the treatment plant and tap water samples were successively collected in January, February and March 2008. For raw, clarified and treated waters, only one sample was taken per month since the raw water characteristics remained fairly unchanged during the sampling period. The water treatment stages and reagents used were also unchanged during that period. On the other hand, 30 samples of tap water were collected at the rate of 10 samples per month from the same sampling points. The sampling points were spread out over the study area. The different samples were subjected to DOC, UV absorbance at $254 \mathrm{~nm}\left(\mathrm{UV}_{254}\right)$, turbidity and EEM data analyses.

\section{Analysis}

Dissolved organic carbon analysis

A Shimadzu TOC-VCSH total carbon analyzer was used to analyse organic carbon in raw and treated waters by combustion at $680^{\circ} \mathrm{C}$. Samples to measure organic carbon concentration were collected using amber glass bottles previously rinsed with nitric acidic solution (20\%) and copious amounts of analytical grade water (Milli-Q) and then heated overnight at $500^{\circ} \mathrm{C}$. Each sample was analyzed thrice and the average value was considered as the DOC data.

\section{EEM data measurements}

All samples (from raw and treated waters) were stored at room temperature (approximately $20^{\circ} \mathrm{C}$ ), to minimize temperature influence. Furthermore, they were filtered through a micro-filtration membrane $(0.45 \mu \mathrm{m})$ prior to analysis, to remove all the insoluble organic particles. 
An RF - 5301 PC Shimadzu spectrofluorometer equipped with a 150 W xenon lamp was used. Excitation (Ex) wavelength was set from 220 to $500 \mathrm{~nm}$, and emission (Em) wavelength from 250 to $600 \mathrm{~nm}$. Ex and Em increment were $10 \mathrm{~nm}$ and $1 \mathrm{~nm}$, respectively, with a slit of $10 \mathrm{~mm}$ for both Ex and Em. EEMs were measured using $1-\mathrm{cm}$ path length quartz cells. In order to confirm the consistency of measurement conditions, scans of quartz cell containing analytical grade water (Milli-Q) were run systematically and the intensity of the Raman line of water at $348 \mathrm{~nm}$ excitation wavelength was recorded. The mean Raman value during the study period was $10.5 \pm 0.6$ intensity units (required value $=10 \pm 2$ ). All the fluorescence intensities were corrected to a Raman peak intensity of 10 units. TOC values from raw water $(10.66 \pm 0.27 \mathrm{mg} / \mathrm{L})$ were such that an inner-filter correction was applied. Sample dilution to a concentration at which the inner-filter effects are negligible was used following Baker et al. (2004). The dilution factor was varied from 1 to 10 .

\section{UV absorbance and turbidity measurements}

$\mathrm{UV}_{254}$ absorbance was measured by Hitachi $\mathrm{U}-2001$ spectrophotometer. The specific ultraviolet absorbance (SUVA) was calculated as the UV absorbance at $254 \mathrm{~nm}(\mathrm{~cm}-1)$ per mass of carbon (DOC in $\mathrm{mg} / \mathrm{L}$ ). Differences in SUVA for water samples collected at different locations or times reflect inherent structural differences in the material containing the DOC. According to Imai et al. (2001) and Weishaar et al. (2003), the SUVA is a very useful parameter for evaluating the characteristics of DOM in waters. Turbidity, on the other hand, was measured with a Hach $2100 \mathrm{P}$ turbidimeter.

\section{RESULTS AND DISCUSSION}

\section{Raw water characteristics}

The chemical characteristics of the water from Agbo reservoir are summarized in Table 1.

Table 1 - Chemical characteristics of raw water from Agbo reservoir

\begin{tabular}{lc}
\hline & Raw water \\
\hline TOC (mg C/L) & $10.66 \pm 0.27$ \\
DOC $(\mathbf{~ m g ~ C / L ) ~}$ & $9.93 \pm 0.34$ \\
POC $(\mathbf{m g} / \mathbf{L})$ & $0.73 \pm 0.61$ \\
SUVA $\left(\mathbf{m}^{-1} \mathbf{L} \mathbf{~ m g}^{-1}\right)$ & $3.75 \pm 0.49$ \\
pH & $6.57 \pm 0.04$ \\
Turbidity (NTU) & $14.21 \pm 6.86$ \\
Temperature & $26.32 \pm 1.02$ \\
\hline
\end{tabular}

SUVA values are used to distinguish autochthonous and allochthonous sources of DOM. When SUVA $\geq 4 \mathrm{~m}^{-1} \mathrm{~L} \mathrm{mg}^{-1}$, terrestrially-derived DOM are admitted to be dominant (Edzwald and Van Benschoten, 1990; Westerhoff and Anning., 2000). The SUVA of the Agbo reservoir $(3.75 \pm 0.31 \mathrm{~m}-1 \mathrm{~L} \mathrm{mg}-1)$ indicates that autochthonous DOM production prevails within the reservoir. Autochthonous DOM results mainly from microbial activity and algal bloom. 
The concentration of particulate organic carbon accounting for TOC is weak, implying that the organic matters from the Agbo reservoir are rather soluble.

Raw water samples were then subjected to EEM fluorescence spectroscopy to distinguish the different classes of DOM.

An example of EEM spectrum (Figure 2) qualitatively indicates the DOM composition. Three peaks have been detected in all samples. Peak T is present at $\lambda_{\mathrm{ex}}=230-240$ and emission $\lambda_{\mathrm{em}}=350-400$. Peak $A$ is observed at $\lambda_{\mathrm{ex}}=240-250$ and emission $\lambda_{\mathrm{em}}=440-450$. A third fluorescence centre (Peak C) is observed at $\lambda_{\mathrm{ex}}=330-340$ and emission at $\lambda_{\mathrm{em}}=440-450$. These peaks have been widely identified in previous studies (Coble, 1996; Parlanti et al., 2000; Hudson et al., 2008).

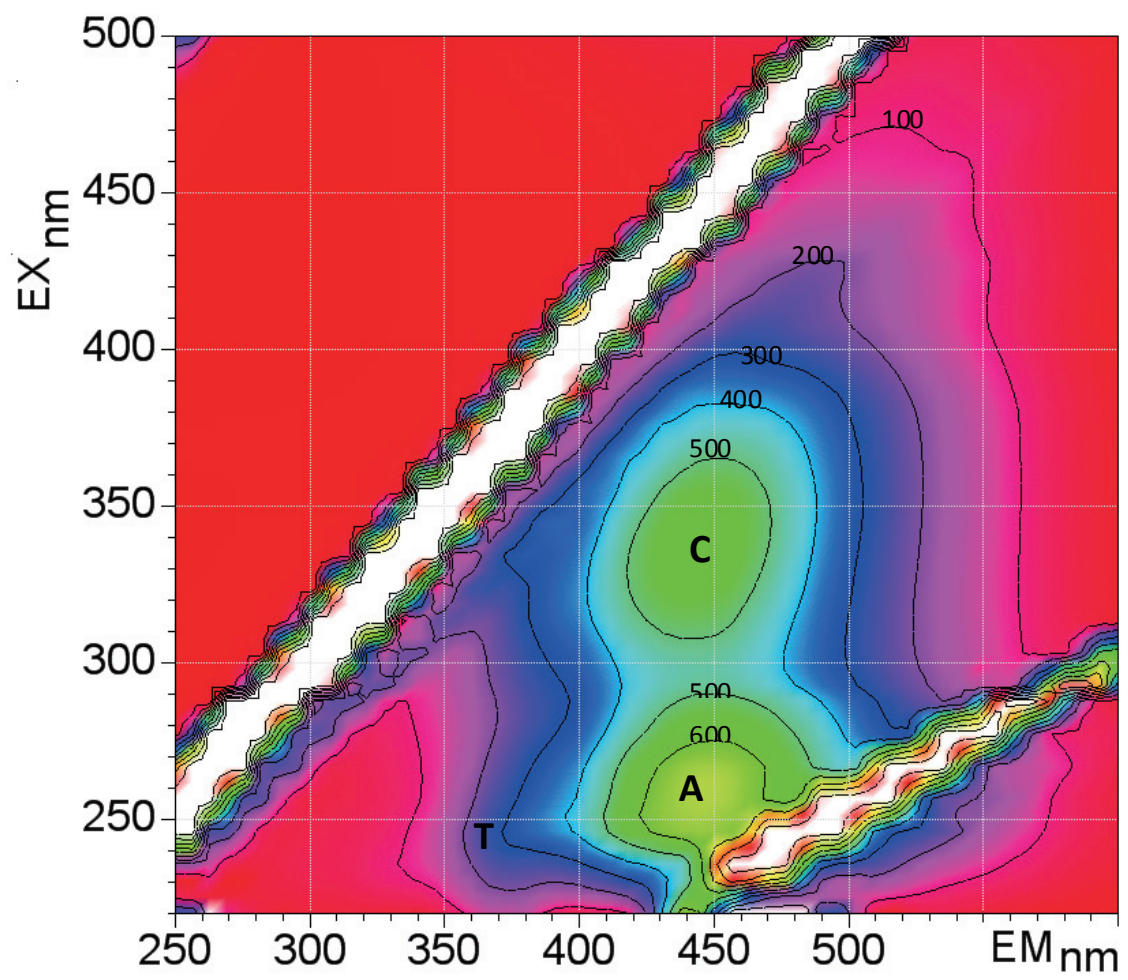

Fig. 2 - Fluorescence EEM of the Agbo reservoir raw water (Sample diluted 8 fold). Fluorophores $\mathrm{A}$ and $\mathrm{C}=$ Humic-like; Fluorophore $\mathrm{T}=$ Tryptophan-like

Peak T is identified as Tryptophan-like. Tryptophan-like fluorescence may be exhibited by natural waters where tryptophan is present as 'free' molecules or bound in proteins, peptides or humic structures. It is related to microbial activity or algal bloom within the system.

Peaks $\mathrm{A}$ and $\mathrm{C}$ are related to humic-like (mainly humic and fulvic acids) and derived from the catchments mainly through the decay of terrestrial plant material and subsequent leaching of partial decomposition products. Humic and fulvic acids are the most common fluorophores in natural surface waters. 


\section{Treated water characteristics}

Characteristics of water at different stages of treatment

The water treatment process at Agboville leads to about $46 \%$ of organic matter removal at the treatment plant before the release of water to the distribution system. However, within the distribution system (tap water), the DOC concentration increases from $5.01 \pm$ 0.57 in treated water at the treatment plant to $6.87 \pm 1.23(27 \%)$ in tap water (Table 2). The turbidity also increased during the course of water within the distribution system whereas chlorine was consumed. This suggests a source of organic matter within the distribution system.

Table 2 - Chemical characteristics of water at different stages of treatment

\begin{tabular}{lccccc}
\hline & $\begin{array}{c}\text { DOC } \\
(\mathbf{m g} / \mathbf{l})\end{array}$ & $\begin{array}{c}\mathbf{C l}_{\mathbf{2}} \\
(\mathbf{m g} / \mathbf{l})\end{array}$ & $\begin{array}{c}\text { SUVA } \\
\left(\mathbf{m}^{-1} \mathbf{l ~ m g} \mathbf{~ m}^{-1}\right)\end{array}$ & $\begin{array}{c}\text { Turbidity } \\
(\mathbf{N T U})\end{array}$ & pH \\
\hline $\begin{array}{l}\text { Clarified water } \\
\text { (not disinfected) }\end{array}$ & $5.73 \pm 0.62$ & $0.08 \pm 0.03$ & $2.1 \pm 0.10$ & $0.84 \pm 0.31$ & $5.74 \pm 0 ; 09$ \\
& & & & & \\
$\begin{array}{l}\text { Treated water } \\
\text { Treatment plant) }\end{array}$ & $5.01 \pm 0.57$ & $2.83 \pm 0.92$ & $2.02 \pm 0.08$ & $0.89 \pm 0.33$ & $6.33 \pm 0.39$ \\
Tap water & $6.87 \pm 1.23$ & $1.06 \pm 0.80$ & $2.01 \pm 0.10$ & $2.01 \pm 1.67$ & $6,39 \pm 0.42$ \\
\hline
\end{tabular}

The SUVA value remains practically constant, indicating no qualitative change in the DOM composition since SUVA increases with aromatic carbon containing more carbon-to-carbon bonds (Weishaar et al., 2003, Izbicki et al., 2007). Edzwald and Van Benschoten (1990) and Uyak et al. (2007) demonstrated that SUVA relates closely to the amount of dissolved aromatic organic matter removed, because aromatic humic substances have a great affinity with aluminium during coagulation. The increase of organic matter within the distribution system is the evidence that the treatment process at the treatment plant is inefficient. Indeed, by optimizing the coagulation-flocculation process of raw water from the same reservoir (Agbo), Gone et al. (2008) obtained $70 \%$ of organic matter removal. These authors showed that $\mathrm{pH}$ and aluminum dose were the most important parameters controlling the efficiency of DOM removal. In all water treatment plants in Côte d'Ivoire, the variation in $\mathrm{pH}$ of the coagulation-flocculation process is the consequence of aluminium sulphate addition responding to variable water turbidity and organic matter content, rather than the result of deliberate $\mathrm{pH}$ adjustment. The role of $\mathrm{pH}$ is particularly significant insofar as it determines at the same time the electrical charge of organic and inorganic colloids, and it is a major factor in the hydrolysis of aluminium salts (Ye et al., 2006).

It is likely that the poor organic matter removal may lead to microbial activity increase, biofilm formation and sludge deposit within the distribution system. This hypothesis may be confirmed since the water turbidity also increases in tap water. Gauthier et al. (1999) showed that deposits within water distribution systems contain a reserve of organic matter which can contaminate the water carried by the distribution system. Transfer of organic matter from deposits to water occurs with the change in water flow rate within the water distribution network (Gauthier et al., 2001). When the chlorination is not applied correctly, bacterial growth within the network can also release organic 
matter, thereby increasing its concentration in water (Fass et al. 2002). The organic matter resulting from microbial activities is well known to be less light-absorbing (Weishaar et al., 2003) and may justify the SUVA value remaining constant.

\section{EEM characterization of finished water at the treatment plant}

Treated water and tap water samples were also subjected to EEM fluorescence spectroscopy. An example of each type of water (treated and tap water) is presented in Figure 3.

The EEM spectrum of treated water (Figure 3a) highlights the different fluorophores that remained in water after the treatment process. Three compounds are identifiable as raw water, humic-like ( $\mathrm{C}$ and $\mathrm{A}$ ) and tryptophan-like $(\mathrm{T})$. Except for the variation of the different fluorophores intensities, no significant difference occurred in the treated water spectrum compared to the raw water one. The EEM spectrum of tap water (Figure 3b) also presents the same three fluorophores. The particularity of the tap water spectrum is that the peak $\mathrm{T}$ is well individualized, giving evidence of an increase of tryptophan-like material within the water distribution network. As stated above, peak $\mathrm{T}$ is related to bacterial activity and may represent the presence of a bioavailable, labile organic substrate or the product of microbial activity (Cammack et al., 2004; Nguyen et al., 2005; Elliot et al., 2006; Urban-Rich et al., 2006). For this reason, it is considered that analysis of the fluorescence intensity of the tryptophan-like region can be used to indicate the size and activity of the microbial community (Hudson et al., 2008). Waste waters including sewage effluents (Reynolds, 2002; Chen et al., 2003), farm wastes (Baker, 2002) and landfill leachates (Baker and Curry, 2004) have been found to be rich in microbial derived peak $\mathrm{T}$ fluorescence and this peak has been used as tracer of waste waters in natural waters (Baker and Inverarity, 2004; Baker et al., 2004). However, the peak $\mathrm{T}$ has not been used to investigate microbial activity within water distribution network. The increase of peak $\mathrm{T}$ within the distribution network is the evidence of microbial community development due to the inefficiency of organic matter removal during the water treatment process.

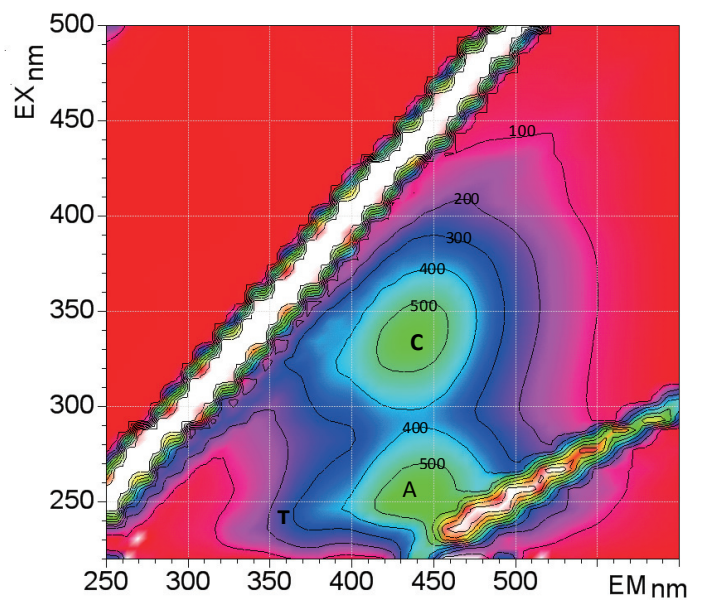

(a)

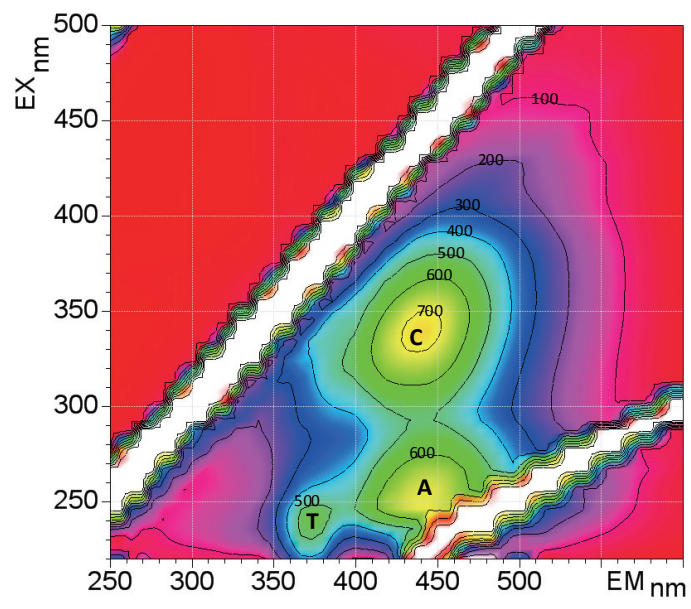

(b)

Fig. 3 - Fluorescence EEMs of treated water at the treatment plant before water release in the distribution system (a) and in tap water (b). 
In order to better characterize the evolution of each fluorophore from the raw water treatment to tap water, the fluorescence intensities (FI) were used to calculate the removal or increasing percentage of each fluorophore (Figure 4). Indeed, the intensity of a peak can be used as a relative measure of the concentration of the fluorophore depending upon the fluorophore (Hudson et al., 2008). It appears that the different fluorophores are removed significantly during the water treatment process whereas they increase again within the distribution network, suggesting a production of organic matter within the distribution system. Cammack et al. (2004) and Elliot et al. (2006) indicate that observation of the peak $\mathrm{T}$ is actually an observation of the balance of decline in substrate and increase in microbial community. However in this study, humic-like (A and $\mathrm{C}$ ) and tryptophan-like (T) peaks increase $(31.13 \%, 34.34 \%$ and $59.51 \%$ for peak $\mathrm{A}$, peak $\mathrm{C}$ and peak $\mathrm{T}$, respectively). This suggests a continuous accumulation of organic matter due to the inefficiency of organic matter removal at the water treatment plant as stated above.

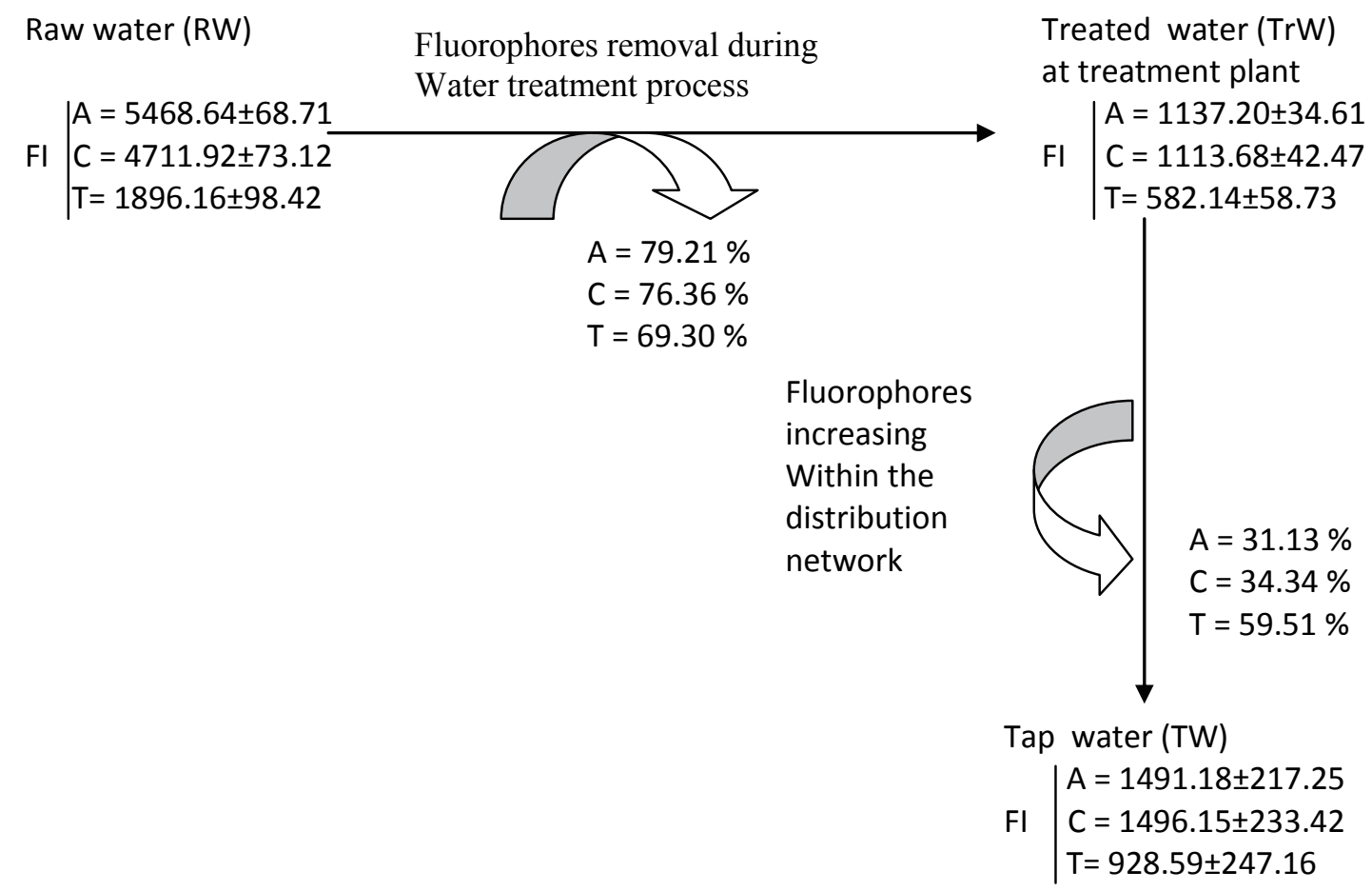

Fig. 4 - Quantitative evolution of the differents fluorophores from raw water to tap water using fluorescence intensities (FI).

At Agboville, small particles are frequently observed in glasses of water when they are allowed to stand, confirming the hypothesis that deposits occur within the network. This leads to frequent complaints of consumers. Thus, some consumers prefer drinking limpid water from wells even if well waters are not protected from contamination.

The remaining organic matter above all the humic-like compounds in water after treatment is of great concern since humic-like compounds are the main source of 
precursors that contribute to the formation of disinfection by-products (DBPs) during water treatment (Yang et al., 2008). Chlorine and its related species react with organic matter in water to produce DBPs (Hamidin et al., 2008). DBPs in water system are of great concern due to their potentially adverse health effects (Krasner et al., 2006).

For this reason, effective removal of DBP precursors is one of the major challenges in modern drinking water treatment (Uyak et al., 2007).

Several epidemiological studies have revealed that there is an association between health effects and exposure to DBPs. King et al., (2000a) and Wright et al. (2003) noted a relationship between THMs and adverse birth outcomes. King and Marrett (1996) and King et al. (2000b) identified an association between THMs (a DBP) and the risk of bladder and colon cancer, respectively. Also, Hinckley et al. (2005) and Wright et al. (2004) found that exposure to dichloroacetic acid and trichloroacetic acid (all DBPs) was linked to a risk of growth reduction in infants. It also resulted in pregnancy loss (Bielmeier et al., 2001) and decrease in sperm mobility (Klinefelter et al., 1995).

\section{CONCLUSIONS}

The aim of this paper was to evaluate DOM removal and characterize DOM at different stages of water treatment. Investigation results revealed that the 3-dimensional excitation emission matrix (EEM) fluorescence spectroscopy has the potential to be a powerful tool in the measurement and characterization of organic matter in water with particular application in organic matter monitoring from the treatment plant to the distribution network system. The EEM permitted to distinguish three main fluorophores: humic-like (A and $\mathrm{C}$ ) derived from the breakdown of plant material and tryptophan-like $(\mathrm{T})$ related to microbial activity.

The removal of these organic compounds is not sufficient at the water treatment plant and a production of organic matter is identified within the distribution network. The remaining organic matter in water after treatment is of great concern since organic matter and particularly humic-like compounds are the main source of precursors that contribute to the formation of disinfection by-products (DBPs) during water chlorination. Moreover, DBPs have potential adverse health effects. For the succeeding experiments, we will analyze the DBPs in tap water to evaluate the risk of their consumption.

\section{ACKNOWLEDGEMENTS}

The authors wish to thank the French embassy in Côte d'Ivoire for financial support. We also thank technicians of HydroScience Laboratory (Montpellier - France) for their involvement in the chemical analyses.

\section{REFERENCES}

Baker A., 2001. Fluorescence excitation-emission matrix characterization of some sewage impacted rivers. Environ. Sci. Technol., 35, 948-953.

Baker, A. (2002). Fluorescence properties of some farm wastes: implications for water 
quality monitoring. Water Res., 36 (1): 2069-2074.

Baker, A. and Curry, M. (2004). Fluorescence of leachates from three contrasting landfills. Water Res., 38 (10), 2605-2613.

Baker, A. and Inverarity, R. (2004). Protein-like fluorescence as a possible tool for determining river water quality. Hydrol. Process, 18 (15), 2927-2945.

Baker, A. and Spencer, R. G. M. (2004).Characterization of dissolved organic matter from source to sea using fluorescence and absorbance spectroscopy. Sci. Total. Environ., 333, 217-232.

Baker, A., Ward, D., Lieten, S. H., Periera, R., Simpson, E. C. and Slater, M. (2004). Measurement of protein-like fluorescence in river and waste water using a handheld spectrophotometer. Water Res., 38 (12), 2934-2938.

Bielmeier, S. R., Best, D. S., Guidici, D. L. and Narotsky, M. G. (2001). Pregnancy lost in the rat caused by bromodichloromethane. Toxicol. Sci., 59 (2), 309-315.

Cammack, W. K. L., Kalf, J., Prairie, Y. T. and Smith, E. M. (2004). Fluorescent dissolved organic matter in lakes: relationship with heterotrophic metabolism. Limnol. Oceanogr., 49 (6), 2034-2045.

Chen, W., Westerhoff, P., Leenheer, J. A. and Booksh, K. (2003). Fluorescence excitation-emission matrix regional integration to quantify spectra for dissolved organic matter. Environ. Sci. Technol., 37, 5701-710.

Coble, P. G. (1996). Characterization of marine and terrestrial DOM in seawater using excitation-emission matrix spectroscopy. Mar. Chem., 51, 325-346.

Coble, P.G., Green, S.A., Blough, N. V. and Gagosian, R. B. (1990). Characterization of dissolved organic matter in the black sea by fluorescence spectroscopy. Nature, 348, 432-435.

Edzwald, J. K. and Van Benschoten, J. (1990). Aluminium coagulation of natural organic matter. In: Hahn, H.H., Klute R. (Eds.), Chemical water and wastewater treatment, proceedings of the fourth international Gothenburg symposium, october $1-3$.

Elliott, S., Lead, J. R. and Baker, A. (2006). Characterization of the fluorescence from freshwater, planktonic bacteria. Water Res., 40 (10), 2075-2083.

Fass, S., Block, J.C., Boualam, M., Gauthier, V., Gatel, D., Cavard, J., Benabdallah, S., Lahoussine, V. (2002). Release of organic matter in a discontinuously chlorinated drinking water network. Water Res., 37 (3), 493-500.

Gauthier, N., Gérard, B., Portal, J. M., Block, J. C., Gatel, D. (1999). Organic matter as loose deposits in a drinking water distribution system. Water Res., 33, 1014-1026.

Gauthier, N., Portal, J. M., Yvon, J., Rosin, C., Block, J.C., Lahoussine, V., Benabdallah, S., Cavard, J., Gatel, D., Fass, S. (2001). Characterization of suspended particles and deposits in drinking water reservoirs. Water Supply, 1 (4), 89-94.

Goné, D. L., Kamagaté, B., Ligban, R., Seidel, J.L., Batiot, C. and Biémi, J.(2008). Coagulation-Flocculation treatment of a tropical surface water with alum for dissolved organic matter (DOM) removal: Influence of alum dose and $\mathrm{pH}$ adjustment. J. Int. Environ. Appl. \& Sci., 3 (4) 247-257.

Hamidin, N., Yu, Q. J. and Connell, D. W. (2008). Human health risk assessment of chlorinated disinfection by-products in drinking water using a probabilistic approach. Water Res., 42, 3263-3274.

Hinckley, A. F., Bachand, A. M.and Reif, J. S. (2005). Late pregnancy exposures to disinfection by-products and growth-related birth outcomes. Environ. Health Perspect, 113 (12), 1808-1813. 
Hudson, N., Baker, A., Ward, D., Reynolds, D. M., Brunsdon, C., Carliell-Marquet, C. and Browning, S. (2008). Can fluorescence spectrometry be used as a surrogate for the Biochemical Oxygen Demand (BOD) test in water quality assessment? An example from South West England. Sci. Total Environ., 391, 149-158.

Hurst, A. M., Edwards, M. J., Chipps, M., Jefferson, B. and Parson, S. A. (2004). The impact of rainstorm events on coagulation and clarifier performance in potable water treatment. Sci. Total Environ., 321, 219-230.

Imai, A., Fukushima, T., Matsushige, K., and Kim, Y. H. (2001). Fractionation and characterization of dissolved organic matter in a shallow eutrophic lake, its inflowing rivers, and other organic matter sources. Water Res., 35 (17), 4019-4028.

Izbicki, J. A., Pimentel, I. M., Johnson, R., Aiken, G. R. and Leenheer, J. (2007). Concentration, UV-spectroscopic characteristics and fractionation of DOC in stormflow from an urban stream, Southern California, USA. Environ. Chem., 4, $35-48$.

King, W. D., Marrett, L. D. and Woolcott, C.G.(2000b). Case -control study of colon and rectal cancers and chlorination by-products in treated water. Cancer Epidemiol. Biomarkers Prev., 9 (8), 813-818.

King, W.D, Dodds, L., and Allen, A. C. (2000a). Relation between stillbirth and specific chlorination by-products in public water supplies. Environ. Health Perspect, 108 (09), 883-886.

Klinefelter, G. R., Suarez, J. D., Roberts, N. L. and DeAngelo, A. B. (1995). Preliminary screening for the potential of drinking water disinfection by-products to alter male production. Reprod. Toxicol., 9, 571-578.

Krasner, S. W., Sclimenti, M. J., and Means, E. G. (1994). Quality degradation: implications for DBP formation. J. Am. Water Works Assoc., 86, 34-47.

Krasner, S. W., Weinberg, H. S., Richardson, S. D., Pastor, S. J., Chinn, R., Sclimenti, M. J., Onstad, G. D. and Thruston, A. D. (2006). Occurrence of a new generation of disinfection by-products. Environ. Sci. Technol., 40, 7175-7185.

Lee, W. and Westerhoff, P. (2006). Dissolved organic nitrogen removal during water treatment by aluminium sulphate and cationic polymer coagulation.Water Res., 40, 3767-3774.

Nguyen, M-L., Westerhoff, P., Baker, L., Hu, Q., Esparza-soto, M. and Sommerfield, M. (2005). Characteristics and reativity of algae-produced dissolved organic carbon. $J$. Environ. Eng., 131 (11), 1574-1582.

Parlanti, E., Wörz, K., Geoffroy, L. and Lamotte, M. (2000). Dissolved organic matter fluorescence spectroscopy as a tool to estimate biological activity in a coastal zone submitted to anthropogenic inputs. Org. Geochem., 31 (12), 1765-1781.

Reynolds, D. M. (2002). The differentiation of biodegradable and non-biodegradable dissolved organic wastewaters using fluorescence spectroscopy. J. Chem Technol. Biotechnol, 77, 965-972.

Rizzo, L., Belgiorno, V., Gallo, M. and Meriç, S. (2005). Removal of THM precursors from a high-alkaline surface water by enhanced coagulation and behaviour of THMFP toxicity on D. magna. Desalination, 176, 177-188.

Sharp E. L., Parson S. A. and Jefferson B. (2006). Seasonal variations in natural organic matter and its impact on coagulation in water treatment. Sci. Total Environ., 363, 183-194.

Tardiff, R. G. ( 1977). Health effects of organics; risk and hazard assessment of ingested chloroform. J. Am. Water Works Assoc., 69, 658-661. 
Urban-Rich, J., McCarty, J. T., Fernandez, D. and Acuna, J. L. (2006). Larvaceans and copepods excrete fluorescent dissolved organic matter (FDOM). J. Exp. Mar. Biol. Ecol., 332, 96-105.

Uyak, V., Yavuz, S., Toroz, I., Ozaydin, S. and Genceli, E. A. (2007). Disinfection by-products precursors removal by enhanced coagulation and PAC adsorption. Desalination, 216, 334-344.

Weishaar, J. L., Aiken, G. R., Bergamaschi, B. A., Fram, M. S., Fujii, R. and Moppers, K. (2003). Evaluation of specific ultraviolet absorbance as an indicator of the chemical composition and reactivity of dissolved organic carbon. Environ. Sci. Technol., 37, $4702-4708$.

Westerhoff, P.and Anning, D. (2000). Concentrations and characteristics of organic carbon in surface water in Arizona: influence of urbanization. J. Hydrol., 236, 202-222.

Wright, J. M., Schwartz, J. and Dockery, D. W. (2004). The effect of disinfection by-products and mutagenic activity on birth weight and gestational duration. Environ. Health Perspect., 112 (8), 920-925.

Wu, F. C., Tanoue, E. and Liu, C. Q. (2003). Fluorescence and amino acid characteristics of molecular size fractions of DOM in the waters of lake Biwa. Biogeochem., 65, 245-257.

Yan, M., Wang, D., You, S., Qu, J. and Tang, H. (2006). Enhanced coagulation in a typical North-China water treatment plant. Water Res., 40, 3621-3627.

Yang, X., Shang, C., Lee, W., Westerhoff, P.and Fan, C. (2008). Correlations between organic matter properties and DBP formation during chloramination. Water Res., 42 , 2329-2339.

Ye, C., Wang, D., Shi, B., Yu, J., Qu, J., Edwards, M. and Tang, H.(2007). Alkalinity effect of coagulation with polyaluminium chlorides: Role of electrostatic patch. Colloids Surf. A: Physicochem. Eng. Aspects, 294 (1-3), 163-173. 